\title{
Pathogen-driven gastrointestinal cancers: Time for a change in treatment paradigm?
}

\author{
Bauyrzhan Aituov ${ }^{1 *}$, Assem Duisembekova', Assel Bulenova ${ }^{1}$ and Kenneth Alibek ${ }^{1,2}$
}

\begin{abstract}
The regulation of cancerous tumor development is converged upon by multiple pathways and factors. Besides environmental factors, gastrointestinal (Gl) tract cancer can be caused by chronic inflammation, which is generally induced by bacteria, viruses, and parasites. The role of these inducers in cancer development, cell differentiation and transformation, cell cycle deregulation, and in the expression of tumor-associated genes cannot be ignored. Although Helicobacter pylori activates many oncogenic pathways, particularly those in gastric and colorectal cancers, the role of viruses in tumor development is also significant. Viruses possess significant oncogenic potential to interfere with normal cell cycle control and genome stability, stimulating the growth of deregulated cells. An increasing amount of recent data also implies the association of Gl cancers with bacterial colonization and viruses. This review focuses on host-cell interactions that facilitate primary mechanisms of tumorigenesis and provides new insights into novel $\mathrm{Gl}$ cancer treatments.
\end{abstract}

Keywords: Gastric cancer, Colorectal cancer, Liver cancer, Helicobacter pylori, Cytomegalovirus, Epstein-Barr virus, John Cunningham virus, Streptococcus bovis, Hepatitis C virus, Helminthes

\section{Review}

\section{A. Gastric Cancers}

Despite many groundbreaking discoveries in biomedical research, cancer is still a major health risk. Gastrointestinal (GI) cancers account for more than $20 \%$ of all cancers worldwide [1], and this holds true for both developing and developed countries [2].

Although genetic predisposition and lifestyle are considered the leading risk factors for cancer development, increasing clinical data suggest that pathogens may play a more significant role than previously thought. In this review, we focus on the implication of pathogens in tumor development in the three major GI cancers-gastric, colorectal, and liver.

\section{A1. Gastric cancer (GC) and bacterial infections}

Helicobacter pylori colonization of the human gastric mucosa occurs in $50 \%$ of the human population and is a key factor in GC development. Having been categorized as a class I carcinogen by the World Health

\footnotetext{
* Correspondence: baituov@nu.edu.kz

'Nazarbayev University, 53 Kabanbay Batyr Avenue, Astana 010000, Kazakhstan

Full list of author information is available at the end of the article
}

Organization in 1994, and this categorization has been reiterated by the International Agency for Research on Cancer in 2010 [3], H. pylori possess virulence factors such as the cytotoxin-associated gene (cagA) and vacuolating cytotoxin gene (vacA) [4]. The oncoprotein CagA and the type IV secretion machinery are encoded by the cag pathogenicity island (cag PAI). H. pylori employs type IV secretion machinery to insert CagA into the host cell cytoplasm, thus causing cell proliferation, morphologic alterations, and cell motility [5]. These processes are further linked to morphologic alterations of the host cell, such as the loss of cell polarity, dissolution of cellular junctions, remodeling of the extracellular matrix, and activation of the $\beta$-catenin pathway, thus conferring an oncogenic potential to the cell [6]. Parsonnet et al. [7] and Torres et al. [8] reported that CagA-seropositive GC patients have a higher risk of cancer compared to CagA-seronegative patients. H. pylori also transmits Vac A, a bacterial toxin, which inhibits glycogen synthase kinase 3 - $\beta$-regulated signaling leading to $\beta$-catenin release and altered apoptosis as well as cell-cycle regulation $[9,10]$. Additionally, H. pylori expresses an outermembrane protein, BabA, which may cause enhanced inflammation and dense bacterial colonization [11]. 
Therefore, H. pylori strains that possess CagA, VacA, and BabA proteins confer a greater risk of GC induction.

CagA can also interact with VacA to cause the deregulation of nuclear factor of activated T-cell signaling [12]. This leads to p21 expression, which influences the fate of cell cycle and cell differentiation. CagA binds to partitioning-defective and mitogen-activated protein/ microtubule affinity-regulating kinase complexes, resulting in reduced kinase activity and disturbed cell polarity [13]. CagA interaction with E-cadherin affects $\beta$-catenin signaling, leading to intestinal trans-differentiation [14].

Ooi et al. [15] reported the activation of three main oncogenic pathways in the majority of GC patients: (1) proliferation/stem cells were activated in $40 \%$ of the patients, (2) nuclear factor kappa beta (NF- $\kappa \beta$ ) activity was stimulated in $39 \%$ of the patients, and (3) Wnt $/ \beta$ catenin activity was stimulated in $46 \%$ of the GC patients. Deregulation of these three pathways was observed in more than $70 \%$ of the patients diagnosed with GC, which resulted in increased inflammatory cytokine production, abnormal apoptosis, undesirable epithelial cell proliferation/differentiation, and epithelial cell transformation [15].

H. pylori infection causes the activation of oncogenic pathways, thus leading to the aberrant expression of genes that are crucial in gastric carcinogenesis. Hirata et al. [16] found that NF-k $\beta$ is activated by H. pylori and is observed in the majority of GCs. The relationship between $H$. pylori-induced inflammation and oncogenic mechanisms of the Wnt/ $\beta$-catenin and prostaglandin E2 pathways has been established [17]. It is implicated that the activation of both the Wnt and prostaglandin E2 pathways results in the formation of gastric tumors via the metaplasia-carcinoma sequence. CagA deregulates the $\mathrm{Wnt} / \beta$-catenin pathway, and upon interaction with E-cadherin, it destroys the formation of the complex between E-cadherin and $\beta$-catenin. This further causes the activation of the $\mathrm{cdx} 1$ and $\mathrm{p} 21$ genes and promotes the aberrant expression of goblet-cell mucin (MUC2) [14], an intestinal differentiation marker.

H. pylori interferes with epigenetic regulation, particularly via microRNAs (miRNAs). miRNAs are small, noncoding RNA molecules that are involved in the post-transcriptional regulation of gene expression during the processes of cell proliferation and development. Specific miRNAs are recognized as tumor suppressors, because their expression is altered in cancer phenotypes [18]. H. pylori has evolved a mechanism to hijack miRNA, thus suppressing host cellular functions to establish infection. It has recently been observed that miR-21 was upregulated in cells obtained from GC patients and in tissues from patients who were chronically infected with $H$. pylori [18]. miR-21 targets the phosphatase and tensin homolog phosphatase and actin- binding protein tropomyosin I, which are tumor suppressors. Consequently, miR-21 aids in the survival of deregulated cells. It has been reported for the first time that miR-21 is altered in H. pylori infection [18]. Ectopic over-expression of miR-21 promoted cell proliferation and inhibited apoptosis.

According to a study by Li et al. [19], another type of miRNA, miR-222, is upregulated in $H$. pylori-infected GC. miR-222 is known to participate in the progression of cancer by promoting cell proliferation [19], which suggests that $H$. pylori may serve as a cancer inducer by up regulating miR-222. Till date, only miR-21 and miR222 are the two types of miRNAs known to be upregulated in $H$. pylori infection. Further studies are required to investigate the exact role of microRNAs in gastric carcinogenesis.

In addition, there is growing evidence that Helicobacter spp plays a significant role in the bacterial cause of $\mathrm{GC}$ in rodents [20]. H. felis is known to cause GC in C57BL/6 mice, which exhibit a histological progression of cancer similar to that observed in $H$. pylori-infected human subjects. H. felis is different from $H$. pylori in that $H$. felis does not possess PAI and cag genes.

\section{A2. GC and viral infections}

The presence of Epstein-Barr virus (EBV) in the neoplastic cells in GC is defined as EBV-associated gastric carcinoma (EBVaGC). It is estimated that $10 \%$ of the total GC cases are related to EBVaGC, and more than 90,000 patients are diagnosed annually with EBVaGC [21]. There is a strong association between the presence of EBV and gastric carcinoma due to the oncogenic properties of the virus [22]. EBV encodes for the latent viral products Epstein-Barr nuclear antigen 1, EpsteinBarr virus-encoded small RNAs (EBERs), and latent membrane protein 2A (LMP2A), as well as encodes for transcripts from the BamH1 A region, such as EBVencoded BamH1-A reading frame-1.

Epstein-Barr nuclear antigen 1 is constitutively expressed in EBVaGC, because it is vital for maintaining EBV replication in the host [23]. EBERs are present in all patients diagnosed with EBVaGC [24-26]. EBER1 upregulated the expression of insulin-like growth factor, thus promoting the growth of NU-GC-3 gastric cancer cells [27].

LMP2A was reported to be expressed in $50 \%$ of all EBVaGC cases $[28,29]$. It upregulated DNA methyl transferase 1 through signal transducer and activator of transcription 3 phosphorylation, which causes promoter hypermethylation of phosphatase and tensin homolog, a tumor suppressor gene [30]. In addition, following EBV infection, LMP2A increases cell survival in GC cell lines, thus making them resistant to serum deprivation-induced apoptosis [31]. LMP2A plays an important role in carcinogenesis; it modifies 
normal B-cell development and maintains EBV latency [32]. The regulation of viral and cellular gene expression through altered $\mathrm{NF}-\mathrm{\kappa} \mathrm{B}$ activity implies an essential role of LMP2A in carcinogenesis [33]. EBVencoded BamH1-A reading frame-1 leads to an increase in the bcl-2/bax ratio, and as a result, GC cells escape apoptosis [34]. EBVaGCs are resistant to apoptosis compared to EBV-negative GCs, which suggests that resistance to apoptosis is an essential feature of EBVaGCs [35,36]. Moreover, a higher methylation rate of tumor-related genes such as p14ARF, p15, p16INK4A, TIMP3, E-cad, DAPK, and GSTP1 was observed in EBVaGCs compared to EBV-negative GCs [31]. In terms of clinopathologic characteristics, EBVaGC is predominant in males, and the most common location is the proximal stomach, with a high frequency found in diffuse-type gastric adenocarcinoma. Chen et al. [37] showed that the frequency of EBVaGC is significantly higher in gastric remnant carcinoma (GRC) than in conventional gastric carcinoma.

Another virus that is reported to play a role in GC is the human polyomavirus called the John Cunningham virus (JCV). JCV induces oncogenesis by expressing the "transforming antigen" (T-Ag). T-Ag acts as a carcinogen by interacting with p53 and the cellcycle regulator $\mathrm{pRb}$, which consequently leads to an uncontrolled growth of cancerous cells. This leads to the loss of genomic stability, which is manifested as an activation of oncogenes and inactivation of tumor suppressor genes. JCV T-Ag interferes with the genome stability of the cell through the inhibition of homologous recombination during DNA repair [38]. Furthermore, it has been demonstrated that more than $50 \%$ of GC patients show chromosomal instability including loss of heterozygosity and various chromosomal rearrangements [39,40]. Shin et al. [41] revealed the presence of $\mathrm{JCV} \mathrm{T}-\mathrm{Ag}$ in gastric tissues, where T-Ag was present in 21 out of 37 GC patients (57\%). This suggests an association between JCV polyomavirus and GCs. Other studies have shown that JCV T-Ag DNA sequences are present in $80 \%$ to $90 \%$ of colorectal cancers (CRCs) [42,43].

\section{A3. GC and parasitic infections}

The human digestive system is densely populated not only with bacteria and viruses, but also with parasites. The role of parasites in GC tumor progression has been recently elucidated. Toxocariasis was confirmed serologically in five male patients, of which three had GC, and two had CRC [44]. Additionally, there was a case report where Microfilaria was found in a 55year-old man diagnosed with gastric carcinoma, although the underlying mechanism of tumor development still needs to be investigated [45]. Tropheryma whippelii has been strongly associated with specific cases of gastric adenocarcinoma; however, the frequency of this association is considered to be low [46].

\section{B. Colorectal cancer}

According to the American Cancer Society, CRC is the fourth most common cancer in men and the third most common cancer in women, worldwide [20]. Epidemiological data accumulated so far has established an association between CRC development and various environmental factors, such as high-calorie diet and obesity; however, the data seems to be contradictory, and these are not recognized as high-risk factors [47]. Progression to CRC, similar to other cancers, is a multistep process, often with a background of genomic instability. Several molecular hallmarks are characteristic of sporadic CRCs that include chromosomal and microsatellite instability, together with epigenetic silencing via $\mathrm{CpG}$ methylation [48]. In contrast to other GI cancers, a direct causal association between CRC development and pathogen infection (bacteria and viruses) has not yet been established [49]. Therefore, extensive studies have been carried out in the past decade to gain more insight into this field.

\section{B1. CRC and bacterial infections}

Streptococcus bovis bacteremia was associated with both colonic neoplasia and extra colonic malignant diseases, despite the fact that it is known as a commensal of the human GI tract [50]. Antibodies to S. bovis surface antigens have been identified in patients with CRC, where increased IgG titers were more consistent with a chronic rather than an acute infection [51]. Moreover, S. bovis antigens were also detected in polyps, supporting the finding that $S$. bovis infection occurs early during CRC carcinogenesis [51]. As previously mentioned, $H$. pylori is a causal factor in GC development, and therefore might play a role in the pathogenesis of other GI cancers. A number of studies have identified $H$. pylori DNA in biopsies of CRC patients [52,53].

At least three bacterial toxins have been characterized that might trigger cellular proliferation. The Bacteroides fragilis toxin disrupts cell cytoskeleton and activates cMyc and cyclin-D, leading to increased proliferation $[54,55]$. Cytotoxic necrotizing factor produced by Escherichia coli strains activates Rho GTPases and modifies the cytoskeleton, resulting in the stimulation of metastatic activity [56,57]. This toxin also triggers G1-to-S phase transition to induce host genome replication [58]. H. pylori-encoded cag PAI toxin and vacuolating cytotoxin were shown to modulate cell 
division and apoptosis by altering the mitogen-activated protein kinase and epidermal growth factor receptor pathways [59].

Several hypotheses have been proposed to explain the oncogenic potential of bacteria. Inflammation in response to bacterial infection results in elevated production of cytokines and reactive oxygen species (ROS), which in turn leads to the up regulation of cyclooxygenase 2 and NF-kB [60]. ROS production is highly likely to induce neoplastic transformation via DNA damage [61]. Bacteria might either damage DNA or modulate DNArepair pathways, increasing their susceptibility to somatic mutations [56]. Activated cyclooxygenase 2 and NF$\kappa \mathrm{B}$ generally inhibit apoptosis [62]. Furthermore, ROS generation by commensal bacteria, such as $S$. bovis, might also lead to genomic instability and result in mutations [60].

\section{B2. CRC and viral infections}

A number of viruses have also been implicated in CRC pathogenesis. These include JCV, EBV, cytomegalovirus (CMV), and human papillomavirus (HPV), and the functional roles of their genes have been identified in various stages of CRC [49]. For instance, it has been previously reported that JCV DNA sequences are frequently present in the upper and lower GI tracts and in CRCs [63]. Recently, it was demonstrated that T-Ag is involved in Wnt signaling by forming a complex with $\beta$-catenin, which results in the transcriptional activation of $\mathrm{c}-\mathrm{Myc}$ and cyclin D1 [64]. It is currently established that the c-myc gene is over-expressed in nearly 70\% of CRCs [65]. Furthermore, Goel et al. (2006) demonstrated a strong association between $\mathrm{T}-\mathrm{Ag}$ expression and chromosome instability in CRCs [66]. They also revealed a direct link between T-Ag expression and aberrant DNA methylation in CRCs. These data seem to be consistent with the aforementioned tumor-inducing mechanisms employed by JCV in GC patients.

EBV DNA was identified in $32 \%$ of colorectal adenocarcinomas [67], CMV DNA was detected in $80 \%$ of carcinomas and polyps [68], and HPV DNA was identified in $60 \%$ of adenomas and $97 \%$ of carcinomas [69]. These findings were associated with caspase 3 inhibition (in the case of EBV) [67], up regulation of Fos, Jun, and Myc oncogenes (in the case of CMV) [68,70], and inactivation of the tumor suppressors p53 and pRb (in the case of HPV) [71].

\section{Liver cancer}

Liver cancer (the most common form known as hepatocellular carcinoma $[\mathrm{HCC}]$ ) is the sixth most prevalent malignant tumor in the world, with more than 600,000 new cases being diagnosed each year, and is the third most common cause of cancer-related mortality [72]. $\mathrm{HCC}$ is a malignant cancer with a poor prognosis and develops as a complication of liver cirrhosis [73]. Multiple mechanisms have been reported to contribute to the process of liver carcinogenesis [74].

When the regulation of cell growth is impaired, uncontrolled cell division results in HCC. Mutations in growth factors, together with chronic cell injury and regeneration, cause excessive hepatocyte proliferation [75]. Subsequently, immortal cells emerge that are susceptible to DNA damage by ROS or environmental factors, eventually leading to malignant hepatocyte transformation [75]. Although some pathophysiological aspects of liver carcinogenesis are known, we still lack a comprehensive picture of the process.

\section{C1. HCC and viral infections}

Although alcohol-related diseases are known to cause HCC, infection with hepatitis $C$ and hepatitis B viruses ( $\mathrm{HCV}$ and $\mathrm{HBV}$ ) is the most common risk factor [76]. Despite a significant decline in the rates of HBV infection and alcohol-related diseases, $\mathrm{HCV}$ alone still accounts for most HCC cases in the developed world $[77,78]$. In addition to causing $\mathrm{HCC}, \mathrm{HCV}$ infection is shown to induce severe liver fibrosis and cirrhosis, as well as GI bleeding [79]. As in GC and CRC, various mechanisms are implicated in the host-viral interactions that lead to HCC progression [80].

Experimental data suggests that $\mathrm{HCV}$ causes malignant transformation of hepatocytes directly by regulating different signaling pathways [81]. For instance, HCVencoded proteins, such as non-structural proteins $3,4 \mathrm{~B}$, and $5 \mathrm{~A}$, were shown to modulate oncogenic pathways leading to hepatocellular transformation [81].

In $\mathrm{HCC}$ patients, the $\mathrm{HCV}$ core and NS5A proteins have been reported to induce accumulation of $\beta$-catenin molecules that results in impaired Wnt- $\beta$-catenin signaling [81]. As mentioned previously, a similar strategy is employed by viral and bacterial pathogens in GC and CRCs. Furthermore, the HCV core protein was reported to interact directly with $\mathrm{p} 53, \mathrm{p} 21$, and NF-kB [82]. As mentioned previously, pathogens adapt similar mechanisms to modulate signaling pathways in GC and CRCs.

\section{C2. HCC and fungal infections}

Environmental toxins such as fungal aflatoxin are shown to be carcinogenic in some parts of Asia and Africa [77,83]. Recently, the G249T mutation in the p53 gene was found in more than $50 \%$ of HCC patients from Southern Africa and some parts of China $[84,85]$. This mutation results in the expression of a defective p53 and is linked with aflatoxin B1 (AFB1) contamination in the local food [86]. In other geographic regions with undetectable or low levels of AFB1 mycotoxin in food, analogous p53 mutations in HCC were not found [87]. It was later demonstrated 
that the AFB1 mycotoxin acts as a cofactor during existing HBV infection, leading to enhanced hepatocarcinogenesis in these areas of the world [88].

\section{C3. HCC and bacterial infections}

Besides studies on the involvement of viruses and fungi, compelling data are also available on the role of bacteria in the development of HCC. An association between $H$. pylori and liver diseases has been established on the basis of numerous reports on identification of $H$. pylori DNA in various liver diseases [89-91].

Data from animal models suggest that bacterial microorganisms may directly induce carcinogenesis. Hepatic gene expression profiling in $H$. hepaticusinfected mice with advancing hepatocellular dysplasia revealed an up regulation of the putative tumor markers [92]. These tumor markers included H19, which activates insulin-like growth factor-II associated with hepatocarcinogenesis [93]. Moreover, acute-phase inflammatory proteins were also shown to be upregulated in the liver as a result of $H$. hepaticus infection [92].

Enteric Helicobacter bacteria also produce toxins that cause liver tissue damage [94]. It is well known that $H$. hepaticus produces a cytolethal distending toxin (CDT) with DNase activity [95], which may induce tumor development. As seen in CRC and GC, the VacA cytotoxin of $H$. pylori could also be involved in direct hepatocellular damage in vivo [12].

\section{C4. HCC and parasitic infections}

Other than microorganisms, helminthes, all of which are trematodes, are strongly implicated in carcinogenesis [96]. The International Agency for Research on Cancer has categorized Schistosoma haematobium and Opisthorchis viverrini as group 1 and Clonorchis sinensis as group 2 carcinogens [97]. Infection with S. haematobium often leads to urinary bladder carcinoma, whereas the liver flukes $\quad O$. viverrini and $C$. sinensis are linked to the development of bile duct cancer (cholangiocarcinoma) and liver cancer (hepatocarcinoma) in humans $[98,99]$.

Although helminth-induced tumorigenesis may involve a number of complex mechanisms, chronic inflammation is a key feature [100]. Alternatively, parasite eggs and secreted products may cause physical damage leading to hyperplasia of the damaged liver tissue [90].

\section{Concluding remarks: Time for a change in the treatment paradigm?}

Currently, approximately $15 \%-20 \%$ of all cancer cases worldwide and $26.3 \%$ of cancer cases in developing countries are attributable to pathogenic agents [96,101]. This equates to approximately $1,375,000$ preventable cancer deaths per year [96]. It should not be surprising that one in every five malignant tumors can originate from pathogen-induced infection [102]. An increasing amount of data suggests that the frequency with which infectious agents contribute to cancer progression might be more than the aforementioned statistics. It is of crucial importance to consider the burden of infection caused by these pathogens due to the fact that both viral and microbial infections can accelerate the tumor development and tumor progression.

An understanding of the role that these pathogens play in tumor development may lead us towards new cancer treatment options that could subsequently increase the survival of cancer patients. This notion is supported by clinical data; it is reported that $83 \%$ of GCs were eradicated by treatment with the antibiotic, nitazoxanide [103]. To date, the 2-week antibiotic regimen for $H$. pylori has proved effective in reducing the prevalence of precancerous gastric lesions [104]. In addition to antibiotics, the frequent use of aspirin and non-steroidal anti-inflammatory drugs has been suggested as a protective factor in GC $[105,106]$. There was a $50 \%$ reduction in the incidence of GC in patients who took aspirin more often, i.e., 16 times a month, as well as a reduced gastric cancer risk in individuals taking non-aspirin non-steroidal antiinflammatory drugs (NSAIDs). In EBVaGC, demethylating agents such as 5-aza cytidine are suggested as an effective treatment in lytic EBV infection [107].

For the treatment of $\mathrm{CRC}$, thiazolides represent a novel class of antimicrobials against bacterial and viral pathogens, as well as helminthes and protozoan's [108]. Thiazolides have been shown to induce glutathione S-transferase P1 (GSTP1)-dependent cell death in human colon cancer cells infected with a wide range of anaerobic bacteria, viruses, protozoan's, and helminthes [109]. Their efficacy in CRC treatment can be attributed to their antimicrobial nature and this has been demonstrated by different laboratories [110,111]. Interestingly, it was also demonstrated that these antimicrobials induced apoptosis in CRC cells, with no significant side effects on normal colorectal cells [112].

Combined treatment with pegylated interferon plus ribavirin is now accepted as the standard therapy for HCC caused by chronic HCV infection [113]. HCV replication inhibitors, mainly HCV NS3/4A protease and NS5B polymerase, have been approved and are currently in phase II and III trials, which should significantly improve $\mathrm{HCV}$ treatment [114]. Similar antiviral strategies are used to treat virus-induced complications resulting in HCC development [115]. In addition to antiviral therapy, antimicrobial strategies are being successfully employed. The previously mentioned thiazolides have been shown to have a broadspectrum activity against pathogens, not only in CRCs, but 
also in liver cancers and in other pathogen-induced GI carcinomas [110].

With accumulating data, it is becoming clear that there is a need to initiate adjuvant and prophylactic therapy long before starting traditional chemotherapy, especially in malignant GI tumors. This necessitates a detailed understanding of pathogens as promoters, initiators, or complicators of carcinogenesis. Comprehensive knowledge of pathogen-induced carcinogenesis in GI tract cancers will possibly help us reconsider our appreciation for antivirals and antimicrobials in cancer treatment and adapt an optimal approach to cancer therapy in the $21^{\text {st }}$ century.

\begin{abstract}
Abbreviations
Gl: Gastrointestinal; H. pylori: Helicobacter pylori; CMV: Cytomegalovirus; EBV: Epstein-Barr virus; miRNAs: Micro RNAs; H. felis: Helicobacter felis; EBVaGC: EBV-associated gastric cancer; PTEN: Phosphatase and tensin homolog; cagA: Cytotoxin-associated gene A; vacA: Vacuolating cytotoxin gene A; GC: Gastric cancer; PAl: Pathogenicity island; BabA: Blood group antigen-binding adhesion; NF-k $\beta$ : Nuclear factor kappa beta;

PGE2: Prostaglandin E2; C57BL/6: C57 black 6 mice strain; EBERs: Epstein-Bar virus-encoded small RNAs; LMP2A: Latent membrane protein 2A; NUGC3: Human gastric carcinoma line; p14ARF: Alternate reading frame product of the CDKN2A locus; p16Ink4A: Another name for cyclin-dependent kinase inhibitor 2A (CDKN2A); TIMP3: Tissue inhibitor of matrix metalloproteinases 3; DAPK: Death-associated protein kinase A; GSTP1: Glutathione S-transferase P1; JCV: JC virus or John Cunningham virus; pRb: Retinoblastoma protein; CRC: Colorectal cancer; S. bovis: Streptococcus bovis; IgG: Immunoglobulin G; ROS: Reactive oxygen species; HPV: Human papillomavirus;

HCC: Hepatocellular carcinoma; HCV: Hepatitis C virus; HBV: Hepatitis B virus; NS3: NS4B, and NS5A, HCV non-structural proteins 3, 4B, and $5 A$, respectively; H. hepaticus: Helicobacter hepaticus; NSAID: Non-steroidal anti-inflammatory drug.
\end{abstract}

\section{Competing interests}

Authors declare they have no competing interests.

\section{Authors' contributions}

$K A, A D, A B$, and $B A$ performed the literature research and composed the manuscript. All authors read and approved the final manuscript.

\section{Acknowledgements}

We thank Dr. Charles Gilman for constructive comments. This project was funded by the Center for Energy Research at Nazarbayev University.

\section{Author details}

'Nazarbayev University, 53 Kabanbay Batyr Avenue, Astana 010000, Kazakhstan. ${ }^{2}$ Republican Scientific Center for Emergency Care, 3 Kerey and Zhanibek Khan Street, Astana 010000, Kazakhstan.

Received: 21 May 2012 Accepted: 27 July 2012

Published: 8 August 2012

\section{References}

1. Ferlay J, Autier P, Boniol M, Heanue M, Colombet M, Boyle P: Estimates of the cancer incidence and mortality in Europe in 2006. Ann Oncol 2007, 18:581-592

2. Jemal A, Siegel R, Ward E, Xu J: Cancer statistics, 2010. CA Cancer J Clin 2010, 60:277-300.

3. Bornschein J, Malfertheiner P: Gastric carcinogenesis. Langenbecks Arch Surg 2011, 396(6):729-742.

4. Correa P, Piazuelo MB: Helicobacter pylori Infection and Gastric Adenocarcinoma. US Gastroenterol Hepatol Rev. 2011, 7(1):59-64.

5. Hatakeyama M: Linking epithelial polarity and carcinogenesis by multitasking Helicobacter pylori virulence factor CagA. Oncogene 2008, 27(55):7047-7054.
6. Wessler S, Backert S: Molecular mechanisms of epithelial-barrier disruption by Helicobacter pylori. Trends Microbiol 2008, 16(8):397-405.

7. Parsonnet J, Friedman GD, Orentreich N, Vogelman H: Risk for gastric cancer in people with CagA positive or CagA negative Helicobacter pylori infection. Gut 1997, 40(3):297-301.

8. Torres J, Pérez-Pérez Gl, Leal-Herrera Y, Muñoz O: Infection with CagA + Helicobacter pylori strains as a possible predictor of risk in the development of gastric adenocarcinoma in Mexico. Int $\mathrm{J}$ Cancer 1998, 78(3):298-300

9. Nakayama M, Hisatsune J, Yamasaki E, Isomoto $H$, Kurazono $H$, Hatakeyama M, Azuma T, Yamaoka Y, Yahiro K, Moss J, Hirayama T: Helicobacter pylori VacA-induced inhibition of GSK3 through the PI3K/Akt signaling pathway. J Biol Chem 2009, 284(3):1612-1619.

10. Manente L, Perna A, Buommino E, Altucci L, Lucariello A, Citro G, Baldi A, laquinto G, Tufano MA, De Luca A: The Helicobacter pylori's protein VacA has direct effects on the regulation of cell cycle and apoptosis in gastric epithelial cells. J Cell Physiol 2008, 214(3):582-587.

11. Rad R, Gerhard M, Lang R, Schöniger M, Rösch T, Schepp W, Becker I, Wagner H, Prinz C: The Helicobacter pylori blood group antigenbinding adhesin facilitates bacterial colonization and augments a nonspecific immune response. J Immunol 2002, 168(6):3033-3041.

12. Yokoyama K, Higashi H, Ishikawa S, Fujii Y, Kondo S, Kato H, Azuma T, Wada

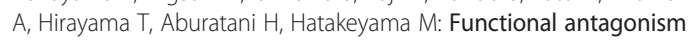
between Helicobacter pylori CagA and vacuolating toxin VacA in control of the NFAT signaling pathway in gastric epithelial cells. Proc Natl Acad Sci U S A 2005, 102(27):9661-9666.

13. Saadat I, Higashi H, Obuse C, Umeda M, Murata-Kamiya N, Saito Y, Lu H, Ohnishi N, Azuma T, Suzuki A, Ohno S, Hatakeyama M: Helicobacter pylori CagA targets PAR1/MARK kinase to disrupt epithelial cell polarity. Nature 2007, 447(7142):330-333.

14. Murata-Kamiya N, Kurashima Y, Teishikata Y, Yamahashi Y, Saito Y, Higashi H, Aburatani H, Akiyama T, Peek RM Jr, Azuma T, Hatakeyama M: Helicobacter pylori CagA interacts with E-cadherin and deregulates the beta-catenin signal that promotes intestinal transdifferentiation in gastric epithelial cells. Oncogene 2007, 26(32):4617-4626.

15. Ooi CH, Ivanova T, Wu J, Lee M, Tan IB, Tao J, Ward L, Koo JH, Gopalakrishnan V, Zhu Y, Cheng LL, Lee J, Rha SY, Chung HC, Ganesan K, So J, Soo KC, Lim D, Chan WH, Wong WK, Bowtell D, Yeoh KG, Grabsch H, Boussioutas A, Tan P: Oncogenic pathway combinations predict clinical prognosis in gastric cancer. PLoS Genet 2009, 5(10):e1000676.

16. Hirata Y, Maeda S, Ohmae T, Shibata W, Yanai A, Ogura K, Yoshida H, Kawabe T, Omata M: Helicobacter pylori induces IkappaB kinase alpha nuclear translocation and chemokine production in gastric epithelial cells. Infect Immun 2006, 74(3):1452-1461.

17. Oshima H, Matsunaga A, Fujimura T, Tsukamoto T, Taketo MM, Oshima M: Carcinogenesis in mouse stomach by simultaneous activation of the Wnt signaling and prostaglandin E2 pathway. Gastroenterology 2006, 131 (4):1086-1095.

18. Zhang Z, Li Z, Gao C, Chen P, Chen J, Liu W, Xiao S, Lu H: miR-21 plays a pivotal role in gastric cancer pathogenesis and progression. Lab Invest 2008, 88(12):1358-1366.

19. Li N, Tang B, Zhu ED, Li BS, Zhuang Y, Yu S, Lu DS, Zou QM, Xiao B, Mao XH: Increased miR-222 in H. pylori-associated gastric cancer correlated with tumor progression by promoting cancer cell proliferation and targeting RECK. FEBS Lett 2012, 586(6):722-728.

20. Global Cancer Facts and Figures: Global Cancer Facts and Figures. 2nd edition.: [http://www.cancer.org/Research/CancerFactsFigures/ GlobalCancerFactsFigures/global-facts-figures-2nd-ed]

21. Ushiku T, Chong JM, Uozaki H, Hino R, Chang MS, Sudo M, Rani BR, Sakuma $\mathrm{K}$, Nagai H, Fukayama M: p73 gene promoter methylation in Epstein-Barr virus-associated gastric carcinoma. Int J Cancer 2007, 120(1):60-66.

22. Shibata D, Weiss LM: Epstein-Barr virus-associated gastric adenocarcinoma. Am J Pathol 1992, 140(4):769-774.

23. Leight ER, Sugden B: EBNA-1: a protein pivotal to latent infection by Epstein-Barr virus. Rev Med Virol 2000, 10(2):83-100.

24. Tokunaga $M$, Uemura $Y$, Tokudome $T$, Ishidate $T$, Masuda H, Okazaki E, Kaneko K, Naoe S, Ito M, Okamura A, et al: Epstein-Barr virus related gastric cancer in Japan: a molecular patho-epidemiological study. Acta Pathol J.jn 1993, 43(10):574-581.

25. Arikawa J, Tokunaga M, Tashiro $Y$, Tanaka S, Sato E, Haraguchi K, Yamamoto A, Toyohira O, Tsuchimochi A: Epstein-Barr virus-positive 
multiple early gastric cancers and dysplastic lesions: a case report. Pathol Int 1997, 47(10):730-734.

26. Fukayama M, Hayashi Y, Iwasaki Y, Chong J, Ooba T, Takizawa T, Koike M, Mizutani S, Miyaki M, Hirai K: Epstein-Barr virus-associated gastric carcinoma and Epstein-Barr virus infection of the stomach. Lab Invest 1994, 71(1):73-81.

27. Iwakiri D, Eizuru Y, Tokunaga M, Takada K: Autocrine growth of EpsteinBarr virus-positive gastric carcinoma cells mediated by an Epstein-Barr virus-encoded small RNA. Cancer Res 2003, 63(21):7062-7067.

28. Sugiura M, Imai S, Tokunaga M, Koizumi S, Uchizawa M, Okamoto K, Osato T: Transcriptional analysis of Epstein-Barr virus gene expression in EBV-positive gastric carcinoma: unique viral latency in the tumour cells. Br J Cancer 1996, 74(4):625-631.

29. Luo B, Wang Y, Wang XF, Liang H, Yan LP, Huang BH, Zhao P: Expression of Epstein-Barr virus genes in EBV-associated gastric carcinomas. World J Gastroenterol 2005, 11(5):629-633.

30. Hino R, Uozaki H, Murakami N, Ushiku T, Shinozaki A, Ishikawa S, Morikawa T, Nakaya T, Sakatani T, Takada K, Fukayama M: Activation of DNA methyltransferase 1 by EBV latent membrane protein $2 \mathrm{~A}$ leads to promoter hypermethylation of PTEN gene in gastric carcinoma. Cancer Res 2009, 69(7):2766-2774.

31. Uozaki H, Fukayama M: Epstein-Barr virus and gastric carcinoma-viral carcinogenesis through epigenetic mechanisms. Int J Clin Exp Pathol 2008, 1(3):198-216.

32. Tao Q, Young LS, Woodman CB, Murray PG: Epstein-Barr virus (EBV) and its associated human cancers-genetics, epigenetics, pathobiology and novel therapeutics. Front Biosci 2006, 11:2672-2713.

33. Stewart S, Dawson CW, Takada K, Curnow J, Moody CA, Sixbey JW, Young LS: Epstein-Barr virus-encoded LMP2A regulates viral and cellular gene expression by modulation of the NF-kappaB transcription factor pathway. Proc Natl Acad Sci U S A 2004, 101(44):15730-15735.

34. Wang Q, Tsao SW, Ooka T, Nicholls JM, Cheung HW, Fu S, Wong YC, Wang X: Anti-apoptotic role of BARF1 in gastric cancer cells. Cancer Lett 2006, 238(1):90-103.

35. Ohfuji S, Osaki M, Tsujitani S, Ikeguchi M, Sairenji T, Ito H: Low frequency of apoptosis in Epstein-Barr virus-associated gastric carcinoma with lymphoid stroma. Int J Cancer 1996, 68(6):710-715.

36. Kume T, Oshima K, Shinohara T, Takeo H, Yamashita Y, Shirakusa T, Kikuchi M: Low rate of apoptosis and overexpression of bcl-2 in Epstein-Barr virus-associated gastric carcinoma. Histopathology 1999, 34(6):502-509.

37. Chen JN, He D, Tang F, Shao CK: Epstein-Barr Virus-associated Gastric Carcinoma: A Newly Defined Entity. J Clin Gastroenterol 2012, 46(4): 262-271.

38. Trojanek J, Croul S, Ho T, Wang JY, Darbinyan A, Nowicki M, Del Valle L, Skorski T, Khalili K, Reiss K: T-antigen of the human polyomavirus JC attenuates faithful DNA repair by forcing nuclear interaction between IRS-1 and Rad51. J Cell Physiol 2006, 206(1):35-46.

39. Seruca R, Castedo S, Correia C, Gomes P, Carneiro F, Soares P, de Jong $\mathrm{B}$, Sobrinho-Simões M: Cytogenetic findings in eleven gastric carcinomas. Cancer Genet Cytogenet 1993, 68(1):42-48

40. Yustein AS, Harper JC, Petroni GR, Cummings OW, Moskaluk CA, Powell SM: Allelotype of gastric adenocarcinoma. Cancer Res 1999, 59(7):1437-1441.

41. Shin SK, Li MS, Fuerst F, Hotchkiss E, Meyer R, Kim IT, Goel A, Boland CR: Oncogenic T-antigen of JC virus is present frequently in human gastric cancers. Cancer 2006, 107(3):481-488.

42. Dyson N, Bernards R, Friend SH, Gooding LR, Hassell JA, Major EO, Pipas JM, Vandyke T, Harlow E: Large T antigens of many polyomaviruses are able to form complexes with the retinoblastoma protein. J Virol 1990, 64(3):1353-1356.

43. Bollag B, Chuke WF, Frisque RJ: Hybrid genomes of the polyomaviruses JC virus, $B K$ virus, and simian virus 40 : identification of sequences important for efficient transformation. J Virol 1989, 63(2):863-872.

44. Park S, Kim YS, Kim YJ, Kyung SY, Park JW, Jeong SH, Lee SP: Toxocariasis masquerading as liver and lung metastatic nodules in patents with gastrointestinal cancer: clinicopathologic study of five cases. Dig Dis Sci 2012, 57(1):155-160.

45. Kumar R: Microfilariae in lymph node aspirate associated with metastatic gastric carcinoma: a case report. Acta Cytol 2010, 54 (3):319-320

46. Cadenas F, Sánchez-Lombraña JL, Pérez R, Lomo FJ, Madrigal Rubiales B, Vivas S, Rodrigo L: Persistent leucocytosis as initial manifestation of
Whipple's disease and development of gastric cancer in the follow up. Rev Esp Enferm Dig 1999, 91(11):785-788.

47. Sandler RS: Epidemiology and risk factors for colorectal cancer. Gastroenterol Clin North Am 1996, 25:717-735.

48. Søreide K, Nedrebø BS, Knapp JC, Glomsaker TB, Søreide JA, Kørner H: Evolving molecular classification by genomic and proteomic biomarkers in colorectal cancer: potential implications for the surgical oncologist. Surg Oncol 2009, 18:31-50.

49. Collins D, Hogan AM, Winter DC: Microbial and viral pathogens in colorectal cancer. Lancet Oncol 2011, 12(5):504-512.

50. Gold JS, Bayar S, Salem RR: Association of Streptococcus bovis bacteremia with colonic neoplasia and extracolonic malignancy. Arch Surg 2004, 139:760-765.

51. Tjalsma H, Scholler-Guinard M, Lasonder E, Ruers TJ, Willems HL, Swinkels DW: Profiling the humoral immune response in colon cancer patients: diagnostic antigens from Streptococcus bovis. Int J Cancer 2006, 119:2127-2135.

52. Jones M, Helliwell P, Pritchard C, Tharakan J, Mathew J: Helicobacter pylori in colorectal neoplasms: is there an aetiological relationship? World J Surg Oncol 2007, 5:51.

53. Grahn N, Hmani-Aifa M, Fransen K, Soderkvist P, Monstein HJ: Molecular identification of Helicobacter DNA present in human colorectal adenocarcinomas by $16 \mathrm{~S}$ rDNA PCR amplification and pyrosequencing analysis. J Med Microbiol 2005, 54:1031-1035.

54. Wu S, Morin PJ, Maouyo D, Sears CL: Bacteroides fragilis enterotoxin induces c-myc expression and cellular proliferation. Gastroenterol 2003, 124:392-400.

55. Toprak NU, Yagci A, Gulluoglu BM, Akin ML, Demirkalem P, Celenk T, Soyletir G: A possible role of Bacteroides fragilis enterotoxin in the aetiology of colorectal cancer. Clin Microbiol Infect 2006, 12:782-786.

56. Hussain SP, Hofseth $\sqcup$, Harris CC: Radical causes of cancer. Nat Rev Cancer 2003, 276:276-285.

57. Lacerda HM, Pullinger GD, Lax AJ, Rozengurt E: Cytotoxic necrotizing factor 1 from Escherichia coli and dermonecrotic toxin from Bordetella bronchiseptica induce p21(rho)-dependent tyrosine phosphorylation of focal adhesion kinase and paxillin in Swiss 3 T3 cells. J Biol Chem 1997, 272:9587-9596.

58. Nougayrède P, Taieb F, De Rycke J, Oswald E: Cyclomodulins: bacterial effectors that modulate the eukaryotic cell cycle. Trends Microbiol 2005, 13:103-110

59. Cover TL, Blanke SR: Helicobacter pylori VacA, a paradigm for toxin multifunctionality. Nature Rev Microbiol 2005, 3:320-332.

60. Marnett $\sqcup:$ Oxyradicals and DNA damage. Carcinogenesis 2000, 21:361-370.

61. Maddocks OD, Short AJ, Donnenberg MS, Bader S, Harrison DJ: Attaching and effacing Escherichia coli downregulate DNA mismatch repair protein in vitro and are associated with colorectal adenocarcinomas in humans. PLoS One 2009, 4(5):e5517.

62. Gupta RA, DuBois RN: Colorectal cancer prevention and treatment by inhibition of cyclooxygenase-2. Nat Rev Cancer 2001, 1:11-21.

63. Ricciardiello L, Laghi L, Ramamirtham P, Chang CL, Chang DK, Randolph AE, Boland CR: JC virus DNA sequences are frequently present in the human upper and lower gastrointestinal tract. Gastroenterology 2000, 119:1228-1235.

64. Enam S, Del VL, Lara C, Gan DD, Ortiz-Hidalgo C, Palazzo JP, Khalili K: Association of human polyomavirus JCV with colon cancer: Evidence for interaction of viral T-antigen and beta-catenin. Cancer Res 2002, 62:7093-7101.

65. Erisman MD, Rothberg PG, Diehl RE, Morse CC, Spandorfer JM, Astrin SM: Deregulation of c-myc gene expression in human colon carcinoma is not accompanied by amplification or rearrangement of the gene. Mol Cell Biol 1985, 5:1969-1976.

66. Goel A, Li MS, Nagasaka T, Shin SK, Fuerst F, Ricciardiello L, Wasserman L, Boland CR: Association of JC virus T-antigen expression with the methylator phenotype in sporadic colorectal cancers. Gastroenterology 2006, 130:1950-1961

67. Song LB, Zhang $X$, Zhang CQ, Zhang Y, Pan ZZ, Liao WT, Li MZ, Zeng MS: Infection of Epstein-Barr virus in colorectal cancer in Chinese. Ai Zheng 2006, 25:1356-1360.

68. Harkins L, Volk AL, Samanta M, Mikolaenko I, Britt WJ, Bland KI, Cobbs CS: Specific localization of human cytomegalovirus nucleic acids and proteins in human colorectal cancer. Lancet 2002, 360:1557-1563. 
69. Kirgan D, Manalo P, Hall M, McGregor B: Association of human papillomavirus and colon neoplasms. Arch Surg 1990, 125:862-865.

70. Bender C, Zipeto D, Bidoia C, Costantini S, Zamò A, Menestrina F, Bertazzoni: Analysis of colorectal cancers for human cytomegalovirus presence. Infect Agent Cancer 2009, 4:6.

71. Ricciardi R, Ghabreau L, Yasmeen A, Darnel AD, Akil N, Al Moustafa A: Role of E6/E7 onco-proteins of high-risk human papillomaviruses in human colorectal carcinogenesis. Cell Cycle 2009, 8:1964-1965.

72. Michielsen P, Ho E: Viral hepatitis B and hepatocellular carcinoma. Acta Gastroenterol Belg 2011, 74(1):4-8

73. Pellicano R, Ménard A, Rizzetto M, Mégraud F: Helicobacter species and liver diseases: association or causation? Lancet Infect Dis 2008, 8(4):254-260.

74. Nissen NN, Martin P: Hepatocellular carcinoma. The high-risk patient. J Clin Gastroenterol 2002, 35(suppl 2):S79-S85.

75. Roberts LR, Gores GJ: Hepatocellular carcinoma. In Textbook of gastroenterology. Edited by Yamada T, Alpers DH, Kaplowitz N, Laine L, Owyang C, Powell DW. Philadelphia: Lippincott Williams \& Wilkins; 2003:2491-2512

76. Yu MC, Yuan JM: Environmental factors and risk for hepatocellular carcinoma. Gastroenterology 2004, 127(suppl 1):S72-S78.

77. El-Serag HB: Hepatocellular carcinoma and hepatitis $C$ in the United States. Hepatology 2002, 36(suppl 1):S74-S83.

78. El-Serag HB: Hepatocellular carcinoma. An epidemiologic view. J Clin Gastroenterol 2002, 35(suppl 2):S72-S78.

79. Masarone M, Persico M: Antiviral therapy: why does it fail in HCV-related chronic hepatitis? Expert Rev Anti Infect Ther 2011, 9(5):535-543.

80. Zemel R, Issachar A, Tur-Kaspa R: The role of oncogenic viruses in the pathogenesis of hepatocellular carcinoma. Clin Liver Dis 2011, 15(2):261-279.

81. Levrero M: Viral hepatitis and liver cancer: the case of hepatitis $C$. Oncogene 2006, 25(27):3834-3847.

82. Banerjee A, Ratna BR, Ranjit R: Oncogenic Potential of Hepatitis C Virus Proteins. Viruses 2010, 2(9):2108-2133

83. Smela ME, Currier SS, Bailey EA, Essigmann JM: The chemistry and biology of aflatoxin $B(1)$ : from mutational spectrometry to carcinogenesis. Carcinogenesis 2004, 22:535-545.

84. Bressac B, Kew M, Wands J, Ozturk M: Selective G to T mutations of p53 gene in hepatocellular carcinoma from southern Africa. Nature 1991, 350:429-431.

85. Hsu IC, Metcalf RA, Sun T, Welsh JA, Wang NJ, Harris CC: Mutational hotspot in the p53 gene in human hepatocellular carcinomas. Nature 1991, 350:427-428.

86. Aguilar F, Hussain SP, Cerutti P: Aflatoxin B1 induces the transversion of $\mathrm{G}->\mathrm{T}$ in codon 249 of the p53 tumor suppressor gene in human hepatocytes. Proc Natl Acad Sci USA 1993, 90:8586-8590.

87. Ozturk M: Genetic aspects of hepatocellular carcinogenesis. Semin Liver Dis 1999, 19:235-242

88. Ming L, Thorgeirsson SS, Gail MH, Lu P, Harris CC, Wang N, Shao Y, Wu Z, Liu G, Wang X, Sun Z: Dominant role of hepatitis B virus and cofactor role of aflatoxin in hepatocarcinogenesis in Qidong, China. Hepatology 2002, 36:1214-1220.

89. Zullo A, Hassan C, Morini S: Helicobacter pylori infection in patients with liver cirrhosis: facts and fictions. Dig Liver Dis 2003, 35(3):197-205.

90. Tiwari SK, Khan AA, Ibrahim M, Habeeb MA, Habibullah CM: Helicobacter pylori and other Helicobacter species DNA in human bile samples from patients with various hepato-biliary diseases. World J Gastroenterol 2006, $12: 2181-2186$

91. Apostolov E, Al-Soud WA, Nilsson I, Kornilovska I, Usenko V, Lyzogubov V, Gaydar Y, Wadström T, Ljungh A: Helicobacter pylori and other Helicobacter species in gallbladder and liver of patients with chronic cholecystitis detected by immunological and molecular methods. Scand J Gastroenterol 2005, 40:1-7.

92. Boutin SR, Rogers AB, Shen Z, Fry RC, Love JA, Nambiar PR, Suerbaum S, Fox $J G$ : Hepatic temporal gene expression profiling in Helicobacter hepaticus-infected A/JCr mice. Toxicol Pathol 2004, 32:678-693.

93. Vernucci M, Cerrato F, Besnard N, Casola S, Pedone PV, Bruni CB, Riccio A: The $\mathrm{H} 19$ endodermal enhancer is required for Igf2 activation and tumor formation in experimental liver carcinogenesis. Oncogene 2000, 19:6376-6385.

94. Taylor S, Fox JG, Yan L: In-vitro hepatotoxic factor in Helicobacter hepaticus, H pylori and other Helicobacter species. J Med Microbiol 1995, 42:48-52.
95. Avenaud P, Castroviejo M, Claret S, Rosenbaum J, Mégraud F, Ménard A: Expression and activity of the cytolethal distending toxin of Helicobacter hepaticus. Biochem Biophys Res Commun 2004, 318:739-745.

96. Mayer DA, Fried B: The role of helminth infections in carcinogenesis. Adv Parasitol 2007, 65:239-296.

97. Monograph on the evaluation of carcinogenic risks to humans: schistosomes, liver flukes and Helicobacter pylori. WHO: International Agency for Research on Cancer 1994, 61:9-175.

98. Fried B, Reddy A, Mayer D: Helminths in human carcinogenesis. Cancer Lett 2011, 305(2):239-249.

99. Thamavit W, Bhamarapravati N, Sahaphong S, Vajrasthira S, Angsubhakorn S: Effects of dimethylnitrosamine on induction of cholangiocarcinoma in Opisthorchis viverrini-infected Syrian golden hamsters. Cancer Res 1978, 38:4634-4639

100. Vennervald BJ, Polman K: Helminths and malignancy. Parasite Immunol 2009, 31(11):686-696

101. Parkin D: The global health burden of infection-associated cancers in the year. Int J Cancer 2006, 118:3030-3044.

102. Franceschi S: Infection: A Major Contributor to the Global Burden of Cancer:. http://www.nypcancerprevention.com/issue/11/cancer_prevention/feature/ franceschi.shtml.

103. Mégraud F, Occhialini A, Rossignol JF: Nitazoxanide, a potential drug for eradication of Helicobacter pylori with no cross-resistance to metronidazole. Antimicrob Agents Chemother 1998, 42(11):2836-2840.

104. Ma JL, Zhang L, Brown LM, Li JY, Shen L, Pan KF, Liu WD, Hu Y, Han ZX, Crystal-Mansour S, Pee D, Blot WJ, Fraumeni JF Jr, You WC, Gail MH: FifteenYear Effects of Helicobacter pylori, Garlic, and Vitamin Treatments on Gastric Cancer Incidence and Mortality. J Natl Cancer Inst 2012, 104 (6):488-492.

105. Malfertheiner P, Megraud F, O'Morain C, Bazzoli F, El-Omar E, Graham D, Hunt R, Rokkas T, Vakil N, Kuipers EJ: Current concepts in the management of Helicobacter pylori infection: the Maastricht III Consensus Report. Gut 2007, 56(6):772-781.

106. Wu CY, Kuo KN, Wu MS, Chen YJ, Wang CB, Lin JT: Early Helicobacter pylori eradication decreases risk of gastric cancer in patients with peptic ulcer disease. Gastroenterology 2009, 137(5):1641-1648. e1-2.

107. Jung EJ, Lee YM, Lee BL, Chang MS, Kim WH: Lytic induction and apoptosis of Epstein-Barr virus-associated gastric cancer cell line with epigenetic modifiers and ganciclovir. Cancer Lett 2007, 247(1):77-83.

108. Hemphill A, Müller J, Esposito M: Nitazoxanide, a broad-spectrum thiazolide anti-infective agent for the treatment of gastrointestinal infections. Expert Opin Pharmacother 2006, 7:953-964.

109. Müller J, Sidler D, Nachbur U, Wastling J, Brunner T, Hemphill A: Thiazolides inhibit growth and induce glutathione-S-transferase Pi (GSTP1)dependent cell death in human colon cancer cells. Int J Cancer 2008, 123 (8):1797-180

110. Hemphill A, Mueller J, Esposito M: Nitazoxanide, a broad-spectrum thiazolide anti-infective agent for the treatment of gastrointestinal infections. Expert Opin Pharmacother 2006, 7(7):953-964.

111. Anderson VR, Curran MP: Nitazoxanide: a review of its use in the treatment of gastrointestinal infections. Drugs 2007, 67(13):1947-1967.

112. Sidler D, Brockmann A, Mueller J, Nachbur U, Corazza N, Renzulli P, Hemphill A, Brunner T: Thiazolide-induced apoptosis in colorectal cancer cells is mediated via the Jun kinase-Bim axis and reveals glutathione-Stransferase P1 as Achilles' heel. Oncogene 2011, 2011:2011. doi:doi: 10.1038/onc.2011.575.

113. NIH Consensus Statement on Management of Hepatitis C. NIH Consens State Sci Statements 2002, 19:1-46.

114. Asselah T, Marcellin P: New direct-acting antivirals combination for the treatment of chronic hepatitis C. Liver Int 2011, 31(Suppl. 1):68-77.

115. Esmat G, El Raziky M, El Kassas M, Hassany M, Gami ME: The future for the treatment of genotype 4 chronic hepatitis C. Liver Int 2012, 32(Suppl 1):146-150

doi:10.1186/1750-9378-7-18

Cite this article as: Aituov et al:: Pathogen-driven gastrointestinal cancers: Time for a change in treatment paradigm?. Infectious Agents and Cancer 2012 7:18 